\section{Real-time PCR typing of single nucleotide polymorphism in DNA containing inverted repeats}

\author{
Pierre Wattiau and David Fretin \\ Veterinary and Agrochemical Research Centre, Brussels, Belgium
}

BioTechniques 41:544-546 (November 2006)

doi 10.2144/000112285

Several real-time PCR options are available to type single nucleotide polymorphism (SNP) in a target DNA sequence (1-3). The most commonly used assays are the $5^{\prime}$ exonuclease $\left(\right.$ TaqMan $\left.^{\circledR}\right)$ assay, the hybridization probe-also called fluorescence energy transfer-assay, and the molecular beacon assay. According to general design rules, probes should fulfill a number of criteria related to their base composition, GC content, secondary structure, and melting temperature. Cross-hybridizing probes and secondary structures must be avoided as they lead to inter- or intraprobe annealing, making them unavailable for hybridization with their target. Unusual GC contents and nucleotide repeats must be avoided as well. Because of these constraints, real-time PCR typing of polymorphic nucleotides located within DNA sequences included in secondary structures remains a technical challenge. In the present report, the usefulness of a pair of customized molecular beacons was investigated for the typing of a SNP included in high GC inverted repeat DNA. Our data show that incorporating bases from the inverted repeat flanking the polymorphic nucleotide in the target sequence yields beacons with good discriminatory capacity, though with unusual thermodynamic properties.

The selected target DNA was a known genetic marker for Burkholderia pseudomallei, a pathogenic bacterium responsible for a severe disease in humans named melioidosis (4). Based on compilations of DNA sequences built for strain typing (5), nucleotide 2952 of gltB in B. pseudomalle $i$ and related species was found polymorphic and useful for the purpose of species identification. $g l t B$ codes for a glutamate synthase in these species and is part of a multiple locus sequence typing scheme (5). However, SNP typing of nucleotide 2952 by real-time PCR was predicted to be unsuccessful because of the high $\mathrm{GC}$ content of the flanking regions and because strong secondary structures are present (Figure 1A). Real-time PCR probe design softwares such as Primer Express $^{\circledR}$ (Applied Biosystems, Foster City, CA, USA) or Beacon Designer (Premier Biosoft International, Palo Alto, CA, USA) failed to compute any discriminatory probes for that SNP, even under poorly stringent conditions.

In order to deal with the secondary structures of the target DNA, the sequence of a native inverted repeat was merged in the beacon sequence in such a manner that it acts dually as part of the beacon's stem and as a
A

B Yellow; TxRd, Texas Red. specific hybridization probe (Figure $1)$. The following 23-mer beacons were synthesized by Eurogentec (Liège, Belgium): 5'-Yakima Yellow ${ }^{\circledR}$ TAGCCGCTTCGGCGTGACGGCTA -3'-DABCYL (BG0075) and 5'-Texas Red-TAGCCGCTTCGGTGTGACGG CTA-3'-DABCYL (BG0106). The beacons had predicted melting temperatures $\left(\mathrm{T}_{\mathrm{m}}\right)$ of $71.4^{\circ} \mathrm{C}$ for the stem part and $67^{\circ} \mathrm{C}$ (BG0075) and $64^{\circ} \mathrm{C}$ (BG0106) for the target complementary part. $T_{m}$ calculation of the stem part was made according to the Zuker algorithm (6) assuming the presence of $50 \mathrm{mM}$ $\mathrm{Na}^{+} / \mathrm{K}^{+}$and $3 \mathrm{mM} \mathrm{Mg}^{2+}$. $\mathrm{T}_{\mathrm{m}}$ calculation of the target-specific probe sequence was done according to SantaLucia (7), assuming $50 \mathrm{mM} \mathrm{Na} / \mathrm{K}^{+}, 400$ $\mathrm{mM}$ probe, and no $\mathrm{Mg}^{2+}$ adjustment. This calculated value was confirmed experimentally by thermal denaturation profiling using a complementary oligonucleotide target. Taken individually, the loop of the beacons had a $T_{m}$ around $40^{\circ} \mathrm{C}$; this value, which is the one calculated usually for molecular beacons, is misleading here as it does not account for the total part of the beacon hybridizing with the target sequence. Compared with the recommended size of 30-40 bases (2), the present beacons were just 23 bases long.

The beacons were incorporated in a real-time PCR assay together with the two amplimers gltB-F $5^{\prime}$ CTCGAAGATCAAGCAGGTCGC-3' and gltB-R 5'-ACGTGATCGGCC CGCGTCGGGCCGGCTTCGG(C/T)GTGACGGCCGAGTATCT

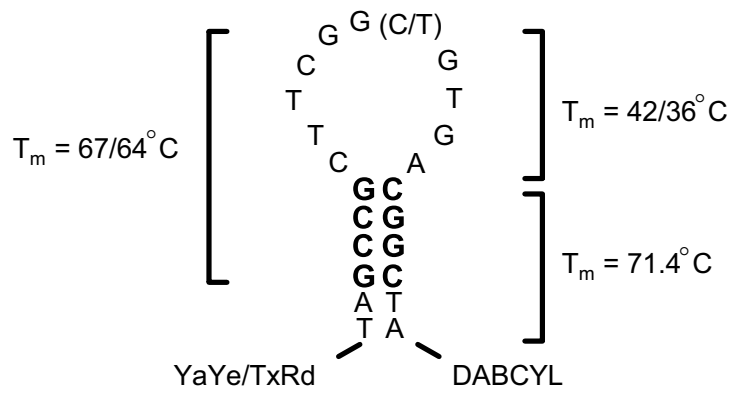

Figure 1. Features of target DNA sequence and real-time PCR probe. (A) Nucleotide sequence of the probe target region in gltB. Inverted repeats are outlined by arrows. The polymorphic nucleotide found at position 2952 is mentioned (C/T). (B) Structure of the molecular beacons used for SNP typing. Nucleotides in boldface are from a native inverted repeat found in the target DNA sequence. Melting temperatures $\left(\mathrm{T}_{\mathrm{m}}\right)$ for the stem, loop, and target-complementary parts are indicated. YaYe, Yakima 


\section{Benchmarks}

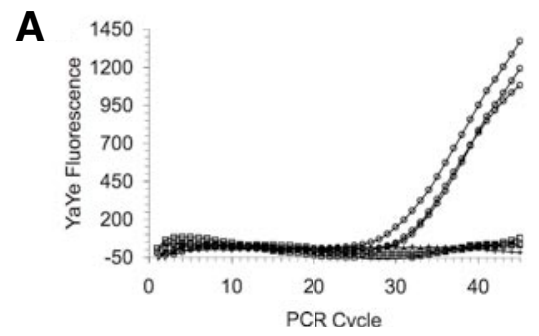

B

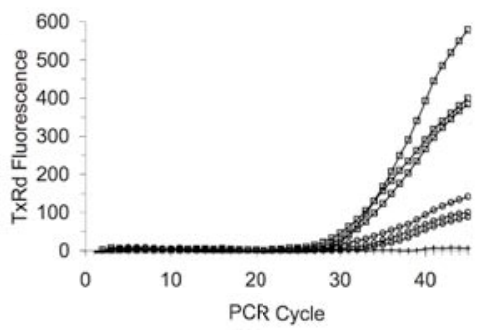

C

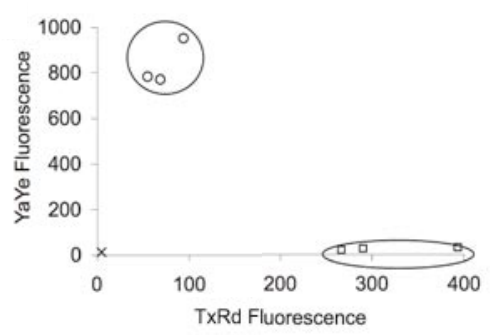

Figure 2. Typical real-time PCR typing results. Total genomic DNA (200 ng) from six strains carrying either the gltB-2952C (circles) or the gltB-2952T allele (squares) was used as a template in $50-\mu \mathrm{L}$ reactions. A negative control is depicted with $\mathrm{X}$ signs. Baseline-subtracted fluorescence was analyzed in optical windows optimized for (A) Yakima Yellow (YaYe) or (B) Texas Red (TxRd) and shown as a function of the PCR cycle. (C) Fluorescence values from the 40th PCR cycle in each optical window were plotted against each other. Each point falls within one out of two delineated clusters corresponding to one allele each.

TTCGC-3' generating a 351-bp PCR fragment. The PCR protocol was 1 cycle of $3 \mathrm{~min}$ at $95^{\circ} \mathrm{C}$, followed by 45 cycles of $30 \mathrm{~s}$ at $95^{\circ} \mathrm{C}, 15 \mathrm{~s}$ at $60^{\circ} \mathrm{C}, 30$ $\mathrm{s}$ at $65^{\circ} \mathrm{C}$ and $20 \mathrm{~s}$ at $72^{\circ} \mathrm{C}$. The realtime PCR instrument was an iCycler ${ }^{\circledR}$ (Bio-Rad Laboratories, Hercules, CA, USA). Assays were performed in 50 $\mu \mathrm{L}$ using 0.4 and $0.1 \mu \mathrm{M}$ primer and probe concentration, respectively, and premixed reagents at the following final concentration: $50 \mathrm{mM} \mathrm{KCl}, 20$ $\mathrm{mM}$ Tris- $\mathrm{HCl}, \mathrm{pH}$ 8.4, $0.8 \mathrm{mM}$ dNTPs, $3 \mathrm{mM} \mathrm{MgCl}_{2}$, and $2.5 \mathrm{U}$ Hot-Start Taq polymerase (Bio-Rad Laboratories). Fluorescence was measured during the temperature step at $65^{\circ} \mathrm{C}$ in optical windows optimized for Yakima Yellow and Texas Red using excitation filters of $530 \pm 15 \mathrm{~nm}$ and $575 \pm 15 \mathrm{~nm}$ and emission filters of $575 \pm 10 \mathrm{~nm}$ and $625 \pm 15 \mathrm{~nm}$, respectively. The beacons displayed good signal-to-noise ratios and could readily type the target SNP as depicted in Figure 2. Beacon BG0075 was remarkably specific, as it yielded no fluorescence signal at all when assayed on the gltB-2952T allele (Figure 2A). Beacon BG0106 was less discriminatory, as it hybridized partially to the gltB-2952C allele (Figure 2B). When plotted against each other, fluorescence intensities clustered into two well-defined zones, each corresponding to a defined sequence type (Figure 2C).

In conclusion, this brief report shows that real-time PCR typing of polymorphic nucleotides located within inverted repeat DNA structures with high GC content can be achieved with the help of molecular beacons. The key element when designing beacons for this purpose is a sequence fragment taken from the target inverted repeat DNA to act dually as a stem structure for the beacon and as part of the probe sequence for target hybridization. Beacons with similar shared-stem structures have been described in the past, though not with the aim of typing SNPs in inverted repeat DNA (8). Such beacons were designed to have one arm of their stem participating in target hybridization and were shown to form more stable duplexes with target molecules compared with conventional beacons. However, their SNP resolution capacity was slightly weaker. Whatever their fine structure, shared-stem molecular beacons described here and elsewhere (8) display atypical $T_{m}$ values and are not ruled according to common probe design softwares. They nonetheless have the potential to perform efficiently in SNP typing, as demonstrated here. The design of similar beacons is likely to facilitate real-time PCR typing of SNPs included in GC-rich inverted repeats, which are frequently encountered in microbial genomes.

\section{ACKNOWLEDGMENTS}

The authors are grateful to Mieke Van Hessche for expert technical assis- tance and to Marc Govaerts for comments.

\section{COMPETING INTERESTS STATEMENT}

The authors declare no competing interests.

\section{REFERENCES}

1. Edwards, K. and J. Logan. 2004. Mutation detection by real-time PCR. In K. Edwards, J. Logan, and N. Saunders (Eds.), RealTime PCR: An Essential Guide. Horizon Bioscience, London.

2. Mhalanga, M.M. and L. Malmberg. 2001. Using molecular beacons to detect single-nucleotide polymorphisms with real-time PCR. Methods 25:463-471.

3. Tapp, I., L. Malmberg, E. Rennel, M. Wik, and A.C. Syvanen. 2000. Homogeneous scoring of single-nucleotide polymorphisms: comparison of the $5^{\prime}$-nuclease TaqMan assay and Molecular Beacon probes. BioTechniques 28:732-738.

4. Wiersinga, W.J., T. van der Poll, N.J. White, N.P. Day, and S.J. Peacock. 2006. Melioidosis: insights into the pathogenicity of Burkholderia pseudomallei. Nat. Rev. Microbiol. 4:272-282.

5. Godoy, D., G. Randle, A.J. Simpson, D.M. Aanensen, T.L. Pitt, R. Kinoshita, and B.G. Spratt. 2003. Multilocus sequence typing and evolutionary relationships among the causative agents of melioidosis and glanders, Burkholderia pseudomallei and Burkholderia mallei. J. Clin. Microbiol. 41:2068-2079.

6. Zuker, M. 2003. Mfold web server for nucleic acid folding and hybridization prediction. Nucleic Acids Res. 31:3406-3415.

7.SantaLucia, Jr., J. 1998. A unified view of polymer, dumbbell, and oligonucleotide DNA nearest-neighbor thermodynamics. Proc. Natl. Acad. Sci. USA 95:1460-1465.

8. Tsourkas, A., M.A. Behlke, and G. Bao. 2002. Structure-function relationships of shared-stem and conventional molecular beacons. Nucleic Acids Res. 30:4208-4215.

Received 5 July 2006; accepted 22 August 2006.

Address correspondence to Pierre Wattiau, Veterinary and Agrochemical Research Centre, Department of Bacteriology and Immunology, Groeselenberg str. 99, B-1180 Brussels, Belgium. e-mail: Pierre.Wattiau@var.fgov.be

To purchase reprints of this article, contact: Reprints@BioTechniques.com 